\title{
Design of fuel system to meet China 6 emissions requirements in hybrid electric vehicle
}

\author{
Shenghua $\mathrm{Qu}^{*}$, and Yanlin Chen \\ Dongfeng Motor Corporation Technical Center, Wuhan, 430058, China
}

\begin{abstract}
Keywords: emission regulations, hybrid power, evaporative emission.

Abstract. Based on the interpretation of GB 18352.6-2016 and combined with the author's actual development experience, the key design points and solutions of the three key problems of fuel system that meet China 6 emission regulations are described, Technical route selection of evaporative emission, definition of technical route of fuel tank and control strategy of tank pressure, evaporative emission control, etc..
\end{abstract}

\section{Introduction}

Emissions and energy saving are two important issues currently facing the automotive industry.

Evaporative emissions means that due to the volatility of gasoline, part of the gasoline in the automobile fuel tank is discharged into the atmosphere in the form of gaseous volatilization directly or through the surface of the fuel tank, carbon canister, etc., causing atmospheric pollution. The national standard "Light Vehicle Pollutant Emission Limits and Measurement Methods (China Phase 6)" (hereinafter referred to as "National VI") has been implemented in most provinces and cities across the country, and its requirements for evaporative emission limits are more stringent than those in the fifth phase.

Plug-in hybrid models can use an external power source to charge the vehicle. During the vehicle's form, the engine may not work and adopt pure electric mode. However, due to factors such as fuel sloshing temperature in the fuel tank, fuel vapor gradually increases. This will cause fuel vapor to overflow into the atmosphere after filling the carbon canister, which will not only pollute the environment, and it also causes the performance of the carbon canister to decrease.

Through the actual development experience of a certain vehicle model, the author of this article introduced the evaporative emission technology route selection, fuel tank technology route definition, pressure relief and refueling control strategy, and evaporative emission control for the fuel system to deal with the above problems.

\footnotetext{
*Corresponding author: qush@dfmc.com.cn
} 


\section{Selection of Evaporative Emission Technology Route}

\subsection{Classification of evaporative emission control systems}

According to the function and working stage of the carbon canister, the National VI emission regulations divide the evaporative emission system into three categories:

Integrated system: Refers to a vehicle fuel evaporation control pollutant system that uses the same hardware to control the direction, storage and desorption of fueling emissions and evaporative emissions. Vehicles equipped with an integrated system usually only use one set of oil and gas routes, one set of desorption routes, a single desorption valve and a single carbon canister (Figure 1).

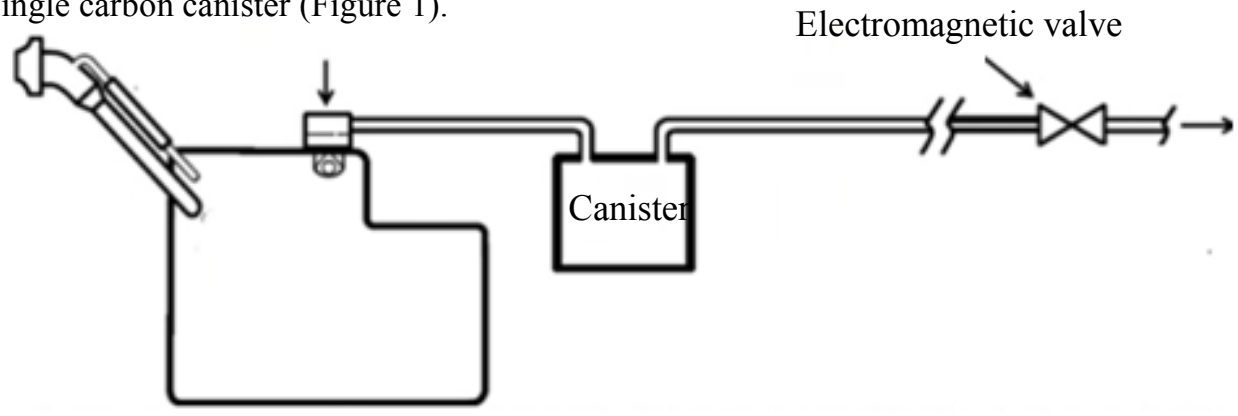

Fig. 1. Diagram of integrated system.

Non-integrated system refers to another vehicle fuel evaporative pollutant control system, which uses different systems to control its refueling emissions and day and night ventilation emissions. Vehicles equipped with non-integrated systems usually use different carbon canisters to control their refueling and day and night ventilation emissions respectively, but depending on different models, they may use the same other related hardware (Figure 2).

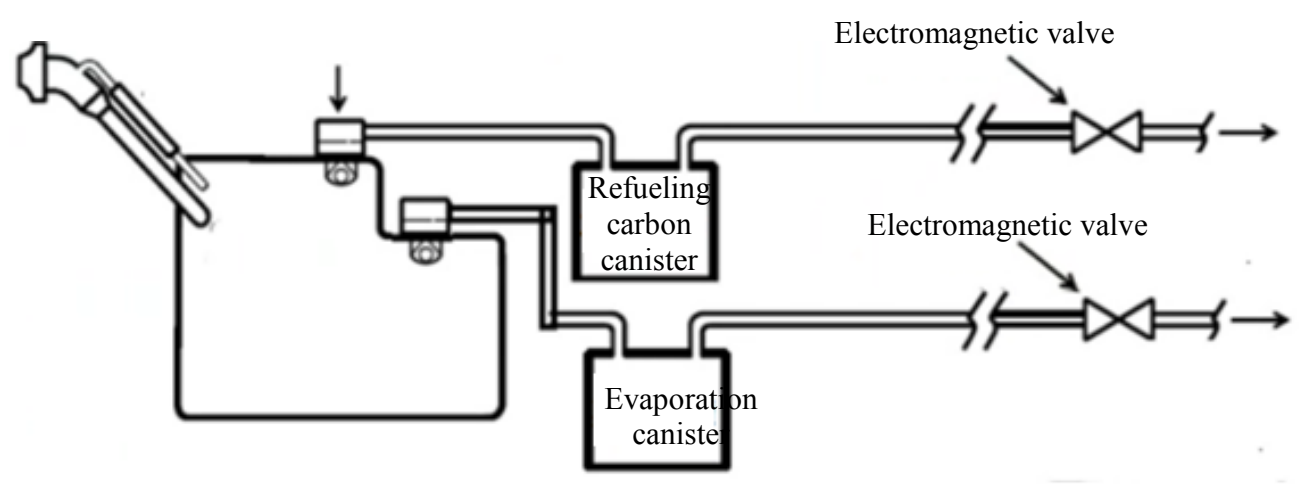

Fig. 2. Diagram of integrated system.

The non-integrated refueling canister-only system (NIRCO full name Non-Integrated refueling canister-only) is a non-integrated system. The main purpose of activated carbon canisters is to absorb only the oil and gas generated during refueling. Other oil and gas produced by non-refueling processes are stored in the fuel tank or discharged to the engine for combustion instead of being stored in the carbon canister. 


\subsection{Evaporative emission test process}

The evaporative emission test process is divided into two types according to the difference of the system form: integrated system and Non-integrated system as shown in Figure 3, and the NIRCO system is tested according to Figure 4.

The test process is divided into four stages:

i) Vehicle pretreatment form and carbon canister pretreatment

ii) High temperature immersion car and high temperature test cycle

iii) Determination of heat soak loss

iv) Determination of day and night ventilation loss

Fig. 4. Non-integral control only refueling system test process.

\subsection{Analysis of evaporative emission technology route}

For plug-in hybrid vehicles, in accordance with the test procedures specified by the Integrated system and the non-integrated system: After completing the above stage i), the vehicle is in a fully charged state, and the carbon canister is in a saturated state after two breakdown loads and high temperature immersion. In the process of stage ii), because the total mileage of the high temperature test cycle is less than the pure electric driving range of the vehicle (generally the pure electric driving range of plug-in hybrid models $>50 \mathrm{~km}$ ), the vehicle is basically driven by batteries, and the carbon canister is basically clean desorption. That is to say, the carbon canister is basically saturated during stages iii) and iv). Therefore, the carbon canister cannot absorb the steam generated by hot soaking and 48-hour day and night ventilation, which will inevitably cause the evaporative emission test results to exceed the limit.

According to the test procedure specified by the non-integrated carbon canister system that only controls refueling emissions: after the completion of the above i) phase test, the vehicle is in power retention mode, and the carbon canister is only in an unsaturated state after $85 \%$ refueling load. During the process of stage ii), since the vehicle is in the state of maintaining power, the engine will frequently start and intervene during the high temperature test cycle, so that the canister can be cleaned normally; therefore, the canister is in the state of Unsaturated state, and due to the cleaning in stage ii), the load is less than $85 \%$ refueling; therefore, the evaporative emission test results can meet the evaporative emission regulations and restrictions.

In summary, the NIRCO system should be selected for hybrid vehicles that meet the requirements of the National VI regulations.

\section{I. Definition of fuel tank technology route}

\subsection{Fuel tank pressure range}

According to the definition of the NIRCO system, the carbon canister only absorbs the oil and gas generated during refueling, and the steam generated during the non-refueling process needs to be stored in the fuel tank or burned by the engine, that is, the NIRCO system needs to use a sealed fuel tank.

Studies have shown that when the temperature of the sealed fuel tank changes from $20^{\circ} \mathrm{C}$ to $35^{\circ} \mathrm{C}$, the maximum pressure of the fuel tank can reach $25.3 \mathrm{kPa}$ (Figure 5); the sealed fuel tank is in the process of hot immersion, normal temperature immersion, and 
48-hour day-night cycle. The pressure will change with temperature changes, the pressure range is generally $-15 \mathrm{kPa}$ to $35 \mathrm{kPa}$;

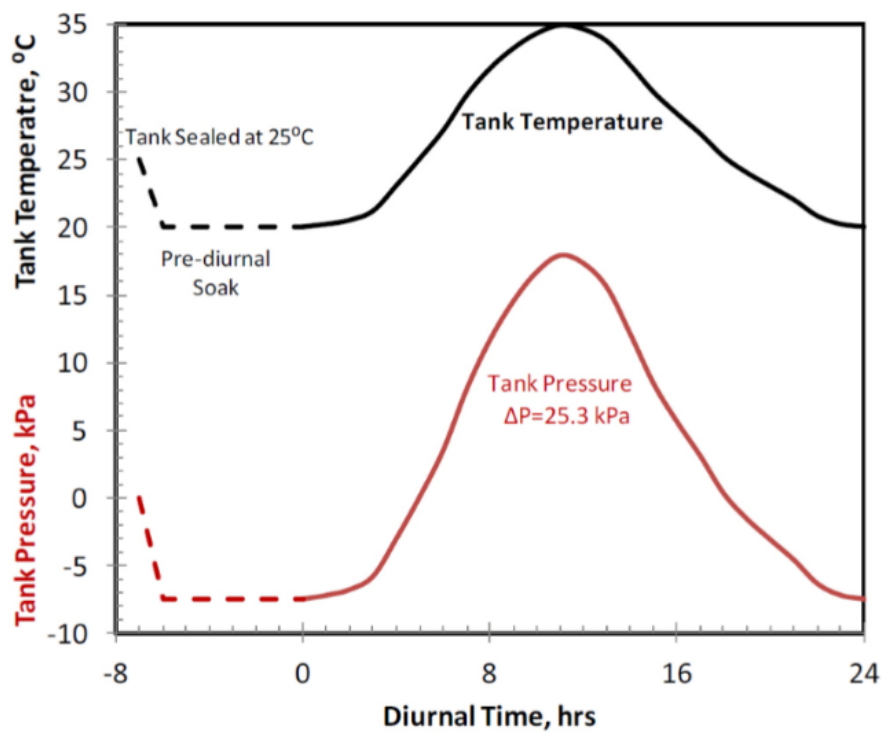

Fig. 5. Diagram of tank pressure and temperature changes.

Generally speaking, the pressure range of traditional plastic fuel tanks is less than $15 \mathrm{kPa}$, which cannot meet the pressure requirements of sealed fuel tanks. Therefore, a high-pressure plastic fuel tank is required.

\subsection{Selection of common materials for fuel tanks}

Common high-pressure fuel tanks have two materials: metal and plastic. Metal fuel tanks can meet the pressure requirements due to the characteristics of the material itself, while plastic fuel tanks need to achieve high pressure resistance through internal structure reinforcement (Figure 6).

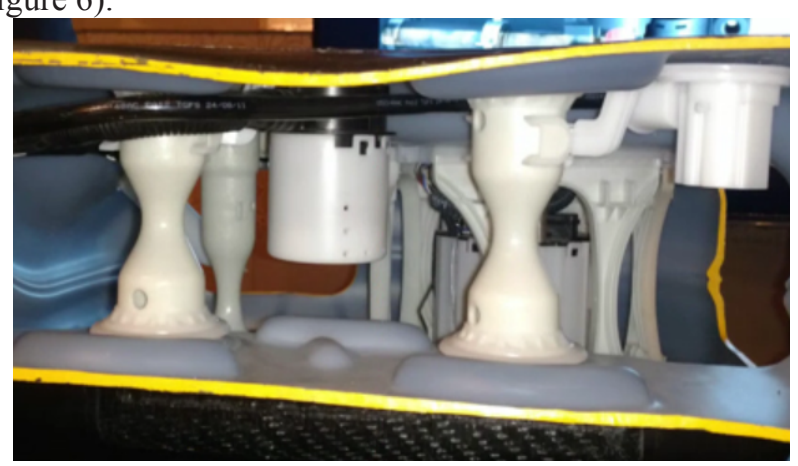

Fig. 6. Schematic diagram of plastic fuel tank reinforced structure.

As shown in Table 1, there are differences between plastic high-pressure fuel tanks and metal high-pressure fuel tanks in terms of performance, development cycle and cost;

In terms of performance, the fuel tank products of both materials can meet the requirements of emission and pressure resistance. Plastic high-pressure fuel tanks have certain advantages in terms of space utilization, corrosion resistance, lightweight and NVH 
performance. In terms of resistance to aging and deformation, metal fuel tanks have more advantages.

At this stage, due to the complex structure, industrialization cycle and development cost of plastic high-pressure fuel tanks, they are significantly worse than metal high-pressure fuel tanks;

In addition, the choice of the two material fuel tanks requires a comprehensive evaluation of the partner resources of different OEMs.

Table 1. Comparison of high pressure fuel tanks of two materials.

\begin{tabular}{|c|c|c|c|}
\hline & Items & High pressure metal & High pressure plastic fuel \\
\hline & $\begin{array}{l}\text { Permeation discharge } \\
\text { performance }\end{array}$ & $\star \star$ & $\star$ \\
\hline & Space utilization & $\star$ & $\star \star$ \\
\hline & $\begin{array}{l}\text { Aging deformation } \\
\text { performance }\end{array}$ & $\star \star$ & $\star$ \\
\hline Perrormance & Pressure resistance & $\star \star$ & $\star \star$ \\
\hline & Corrosion resistance & $\star$ & $\star \star$ \\
\hline & Lightweight & $\star$ & $\star \star$ \\
\hline & NVH performance & $\star$ & $\star \star$ \\
\hline Cycle & Industrialization & $\star \star$ & $\star$ \\
\hline & $R \& D$ expense & $\star \star$ & $\star$ \\
\hline Cost & Industrialization costs & $\star \star$ & $\star$ \\
\hline & Unit cost & $\star \star$ & $\star$ \\
\hline & Note: $\star \star$ refers to & $\star \mathrm{re}$ & good \\
\hline
\end{tabular}

\section{Pressure control strategy of fuel system}

Unlike traditional cars, because the fuel tank is a high-pressure sealing system, its internal pressure is relatively high. When opening the filler cap during refueling, there is a risk of injury from high-pressure fuel vapor. In addition, in order to prevent the fuel vapor from releasing pressure through the fuel filler cap at this time and causing excessive emissions, the problem of fuel vapor pressure relief path should be solved. Therefore, it is necessary to control the pressure in the high-pressure fuel tank system.

The main parts forming the high-pressure fuel tank sealing system include fuel tank assembly, fuel filler cap, fuel tank pressure sensor, fuel vapor isolation valve (hereinafter referred to as FTIV valve), carbon canister assembly, carbon canister solenoid valve, etc. (Figure 7). 


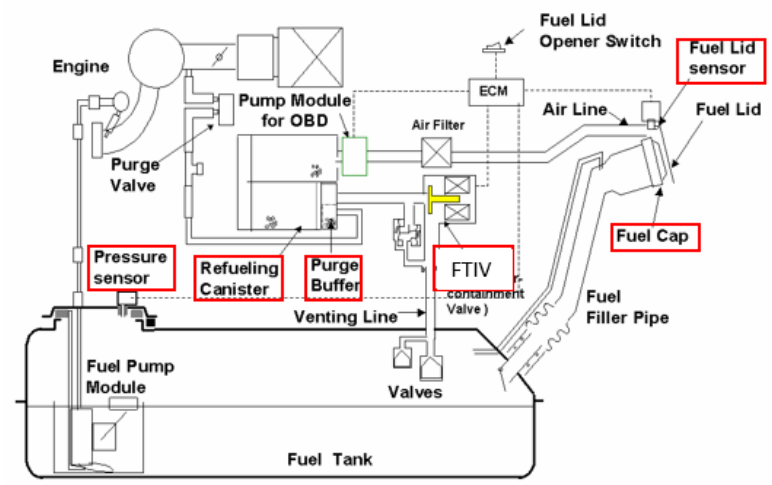

Fig. 7. Schematic diagram of fuel system pressure control system.

The whole system realizes different control through ECU and BCM according to several different working conditions such as driving, parking and refueling.

\subsection{Parking condition}

The FTIV valve is closed to seal the fuel tank. At this time, the fuel vapor in the fuel tank does not flow into the canister but is sealed inside the fuel tank (picture).

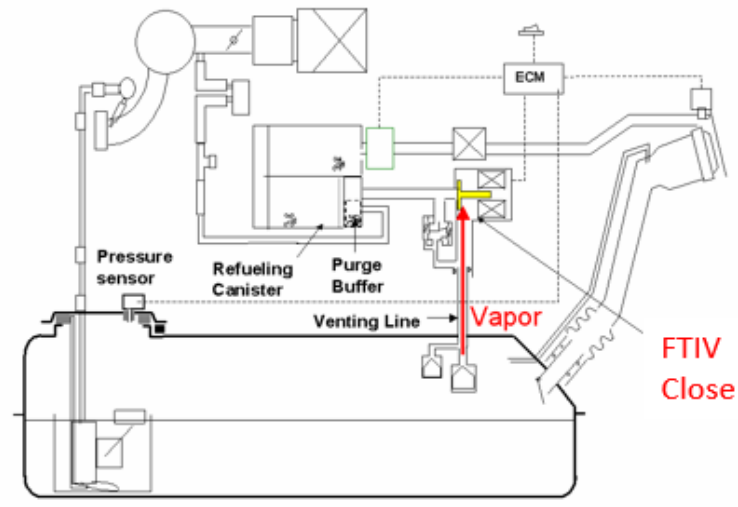

Fig. 8. Schematic diagram of system status when parking.

\subsection{Refueling conditions}

When the driver stops to refuel, the FTIV valve is closed, and the internal pressure of the fuel tank is sometimes high. In this case, refueling may not be completed without a large amount of steam escape. Therefore, the system control of refueling was developed. Before the fuel cap is opened, it can reduce the pressure in the fuel tank to bring it close to the atmospheric pressure to ensure that the driver refuels like a traditional vehicle. The control process is as follows: 


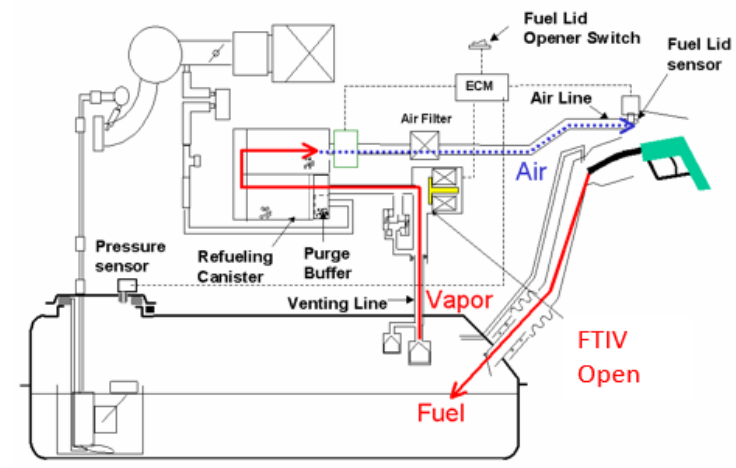

Fig. 9. Schematic diagram of system status when refuelling.

When refueling, the driver operates the switch on the refueling plate cover located on the dashboard or at a suitable position inside. In response to the switch output signal, the electronic control module (ECM) opens the FTIV valve. The pressure in the tank immediately before refueling is generally close to atmospheric pressure. Because when the vehicle is running, it is controlled close to atmospheric pressure. However, there are cases where the pressure in the fuel tank is positive. In these cases, fuel vapor will enter the canister through the vent pipe. The pressure sensor detects the pressure drop in the fuel tank to approach atmospheric pressure, and the driving signal is output to the fuel filler plate cover lock. Then the fuel cap is opened, when the pressure in the fuel tank drops to atmospheric pressure. The driver can refuel without any difficulty. The above required time only takes one or two seconds under normal operating conditions. The fuel vapor generated during refueling is absorbed by the activated carbon in the refueling tank (Figure 9). When the driver finishes refueling and closes the fuel cap, the FTIV valve will be closed in response to the output signal of the fuel cap sensor (the body panel installed behind the fuel cap to complete the fuel control) (Figure 10).

\begin{tabular}{|c|c|c|c|c|}
\hline \multirow[b]{2}{*}{$\begin{array}{l}\text { User's } \\
\text { Operation }\end{array}$} & \multicolumn{4}{|c|}{ Refueling System Operation } \\
\hline & $\begin{array}{l}\text { Fuel L } \\
\text { Opene }\end{array}$ & id & Refueling & $\begin{array}{l}\text { Closing } \\
\text { Fuel Lid }\end{array}$ \\
\hline $\begin{array}{l}\text { Lid Opener } \\
\text { Switch }\end{array}$ & $\begin{array}{l}\text { ON } \\
\text { OFF }\end{array}$ & & & \\
\hline ECM & $\begin{array}{l}\text { ON } \\
\text { OFF }\end{array}$ & & & \\
\hline$\underset{\text { (Solenoid Valve) }}{\text { FV }}$ & $\begin{array}{l}\text { OPEN } \\
\text { CLOSE }\end{array}$ & & & \\
\hline $\begin{array}{c}\text { Tank } \\
\text { Pressure }\end{array}$ & $\begin{array}{l}\text { Threshold } \\
\text { Pressure }\end{array}$ & & & $=\ldots$ \\
\hline $\begin{array}{l}\text { Fuel Lid\& } \\
\text { Lid Sensor }\end{array}$ & $\begin{array}{l}\text { OPEN } \\
\text { CLOSE }\end{array}$ & & & $\dot{8}$ \\
\hline
\end{tabular}

Figure 10. Signal principle diagram when refueling

\subsection{Driving conditions}

When the vehicle is running, due to the thermal influence of the engine, exhaust pipes and other heat radiating components, the temperature of the fuel in the fuel tank may rise, thereby increasing the pressure of the fuel tank. When the FVV is at the maximum opening 
and the control and purification control connections are closed, the engine directly consumes the fuel vapor in the fuel tank, thus preventing the fuel vapor from flowing to the canister. In the actual system, the opening time of FVV depends on the purification flow rate and the pressure in the tank. As the purge flow decreases and the tank pressure increases, if the purge is complete, the FVV will remain closed. Like traditional vehicles, the fuel vapor absorbed by the canister during refueling will be purified by the engine vacuum and will be burned and consumed by the engine when the vehicle is running.

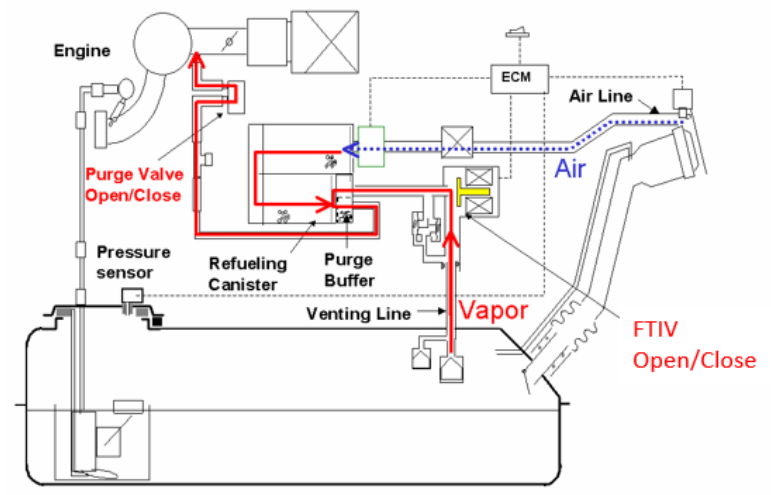

Figure 11. Schematic diagram of system status while driving

\section{Conclusion}

Facing the dual issues of emissions and energy conservation, more and more vehicle companies will launch hybrid vehicles that meet the National VI emission regulations. It is hoped that this article's technical research on evaporative emission technology route selection, fuel tank technology route definition, fuel tank pressure control strategy, and evaporative emission control technology can provide technical support and help to the development of fuel systems for other vehicle companies.

\section{References}

1. Ministry of Environmental Protection. Light-duty vehicle pollutant emission limits and measurement methods (China Phase 6): GB 18352.6-2016 [S]. Beijing: China Environmental Press, 2016.

2. Sam Reddy. Understanding and Designing Automotive Evaporative Emission Control Systems[J], SAE International, 2012

3. Yojiro Iriyama, Masahide Kobayashi, Takuji Matsubara, Yuusaku Nishimura, Ryosuke Nomura and Takashi Ishikawa. Design of A Fuel Vapor-containment System (FVS) to Meet Zero Evaporative Emissions Requirements in a Hybrid Electric Vehicle [J] .SAE International, 2012 